\title{
PEG-Delivered CRISPR-Cas9 Ribonucleoproteins System for Gene-Editing Screening of Maize Protoplasts
}

\author{
Rodrigo Ribeiro Arnt Sant'Ana ${ }^{1}{ }^{\circledR}$, Clarissa Alves Caprestano ${ }^{1}\left(\right.$, Rubens Onofre Nodari ${ }^{1}$ and \\ Sarah Zanon Agapito-Tenfen $2, *$ (D) \\ 1 CropScience Department, Federal University of Santa Catarina, Florianópolis 88034000, Brazil; \\ rodrigoarnt@hotmail.com (R.R.A.S.); clarissacapre@gmail.com (C.A.C.); rubens.nodari@ufsc.br (R.O.N.) \\ 2 GenØk-Centre for Biosafety, Siva innovasjonssenter Postboks 6418, 9294 Tromsø, Norway \\ * Correspondence: sarah.agapito@genok.no
}

Received: 18 August 2020; Accepted: 30 August 2020; Published: 2 September 2020

\begin{abstract}
Clustered regularly interspaced short palindromic repeats (CRISPR)-Cas9 technology allows the modification of DNA sequences in vivo at the location of interest. Although CRISPR-Cas9 can produce genomic changes that do not require DNA vector carriers, the use of transgenesis for the stable integration of DNA coding for gene-editing tools into plant genomes is still the most used approach. However, it can generate unintended transgenic integrations, while Cas9 prolonged-expression can increase cleavage at off-target sites. In addition, the selection of genetically modified cells from millions of treated ones, especially plant cells, is still challenging. In a protoplast system, previous studies claimed that such pitfalls would be averted by delivering pre-assembled ribonucleoprotein complexes (RNPs) composed of purified recombinant Cas9 enzyme and in vitro transcribed guide RNA (gRNA) molecules. We, therefore, aimed to develop the first DNA-free protocol for gene-editing in maize and introduced RNPs into their protoplasts with polyethylene glycol (PEG) 4000. We performed an effective transformation of maize protoplasts using different gRNAs sequences targeting the inositol phosphate kinase gene, and by applying two different exposure times to RNPs. Using a low-cost Sanger sequencing protocol, we observed an efficiency rate of 0.85 up to $5.85 \%$, which is equivalent to DNA-free protocols used in other plant species. A positive correlation was displayed between the exposure time and mutation frequency. The mutation frequency was gRNA sequence- and exposure time-dependent. In the present study, we demonstrated that the suitability of RNP transfection was proven as an effective screening platform for gene-editing in maize. This efficient and relatively easy assay method for the selection of gRNA suitable for the editing of the gene of interest will be highly useful for genome editing in maize, since the genome size and GC-content are large and high in the maize genome, respectively. Nevertheless, the large amplitude of mutations at the target site require scrutiny when checking mutations at off-target sites and potential safety concerns.
\end{abstract}

Keywords: gene editing; mutagenesis; genetically modified; genetically modified organism (GMO); crop breeding; ribonucleoprotein complex (RNP); genetic screening

\section{Introduction}

The development of technologies related to genetic improvement, such as transgenesis and more recently, genome editing, have changed the way humans have grown food for thousands of years. Today, the most promising tool to DNA manipulation is CRISPR (Clustered Regularly Interspaced Short Palindromic Repeats), a gene-editing technology that has been adapted from the bacterial immune system against viral infections [1]. Currently, a target site in the host genome can be reached by an 
endonuclease enzyme (i.e., Cas9) led by a guide RNA molecule (gRNA) that contains the target-specific sequence. This protein complex forms the CRISPR-Cas9 ribonucleoproteins (RNPs) gene-editing system. Cas9 introduces a site-specific double-stranded DNA break (DSB) followed by the natural cell repair of disrupted genome integrity by error-prone non-homologous end-joining (NHEJ) or homology-directed repair (HDR) [2]. Therefore, this tool allows the in vivo modification of the DNA at the gene sequence of interest, with unprecedented speed, and has made it a milestone in manipulating and producing living modified organisms.

Although much is already known about the principles of CRISPR-Cas9 genome editing, the likelihood of different outcomes in terms of resolution, efficiency, accuracy, and DNA modification structure has shown to be species-dependent. Various factors, including target site choice, gRNA design, the properties of the endonuclease, the type of DSB introduced, whether or not the DSB is unique, the quantity of the endonuclease and gRNA, and the intrinsic differences in DNA repair pathways in different species, tissues, and cells will result in differences in the mutation signatures generated in plant species [3].

In the case of maize, most researchers acknowledge that Zea mays L. is an ancient amphidiploid species with a duplicated chromosome number of $n=10$ [4]. Multiple independent domestication events have also contributed to the genetic variability encountered in modern maize [4]. In addition, the genetic variants and the underlying mechanisms influencing variance heterogeneity in maize have so far hidden additive genetic effects and epistatic interaction effects in elite varieties [5]. Therefore, CRISPR can be a useful tool to access genomic regions in the maize genome, which are difficult to achieve by conventional breeding.

While CRISPR technology has already been tested on commercial crops to increase yield, drought tolerance and growth under limited nutrient conditions, improve nutritional properties and develop resistance to plant pathogens [6]; breeding and research of major monocotyledon species, more specifically maize, are still at its infancy. Maize has shown to be an exemption in the plant portfolio for the in silico analysis of potential Cas 9 target sites as only $29.5 \%$ of annotated transcripts matched a specific gRNA [7]. Among eight analyzed plant species, maize had the largest genome, the highest GC content, and the greatest number of annotated transcripts. Thus, reflecting the abundance of highly repetitive DNA and dispersed repeats, which may be challenging to develop unique target sites for the majority of genes in maize [7].

Despite such challenges, CRISPR technology opens up the possibility for genome changes without foreign introgression of DNA vectors. CRISPR-Cas9 technology can be used as RNP complexes without the introgression and expression of a transgenic cassette in the host genome [8]. Such an approach would avoid a number of generations of backcrossing, expression vectors, and other invasive methods of cell penetration (e.g., biolistics) that can lead to gene disruption, including large deletions, partial trisomy, genome shattering events, and plant mosaicism [9]. Overall, these side effects can mask or interfere in the target gene functional analysis, and further additional biosafety concerns prior to commercial release.

CRISPR RNPs can be delivered directly to plant cells without the cell wall. Therefore, prior to transfection, the cell wall must be removed through enzymatic digestion reactions. Protoplast cells are viable in vivo biological material for DNA-free CRISPR delivery in plants. In addition, protoplasts are viable after transfection, which allows further tissue cultivation and propagation.

Delivery of preassembled Cas9 protein-gRNA RNPs or plant DNA-free genome-editing techniques are not exempt from off-target effects but represent an approach in which the effects of Cas9 could be isolated from other more invasive techniques $[8,10,11]$. This approach was first demonstrated in Arabidopsis thaliana, tobacco, lettuce, and rice protoplasts, including the regeneration of gene-edited lettuce [12]. After that, a few successful attempts were also accomplished on grapevine and apple [13], Petunia $\times$ hybrida [14], potato [15], and on soybeans and tobacco using CRISPR-Cpf1 (CRISPR from Prevotella and Francisella), recently named Cas12a (for review, please read Metje-Sprink et al. [8]). Maize and wheat plants with targeted mutations have also been successfully obtained by delivering gold 
particles coated with the RNPs into embryo cells (biolistics), followed by post-bombardment culture and plant regeneration [16]. However, the frequency of obtaining genome-edited plants was relatively low, since only $0.3-0.9 \%$ of regenerated maize plants possessed biallelic mutations [16].

The few studies published on maize genome editing rely mostly on the stable transformation [17-20]. In the manuscript, we delivered Cas9-gRNA RNP into maize leaf protoplasts via polyethylene glycol (PEG)-calcium mediated transfection, and indicated that In/Del mutations occurred with relatively high efficiency of $0.85-5.85 \%$ among the PEG-calcium-treated protoplast. We targeted the inositol phosphate kinase gene (IPK) involved in the phytic acid biosynthetic pathway. To develop a standard protocol for different maize varieties, we designed gRNAs and primers complementary to coding regions in exon three that are conserved in the species, in order to evaluate the efficiency and spectrum of DNA changes generated by CRISPR-Cas9 technology in maize, and also add relevant information to the safety of gene-edited organisms. This efficient and relatively easy assay method for the selection of gRNA suitable for editing of genes of interest will be highly useful for genome editing in maize, since the genome size and GC-content are large and high in the maize genome, respectively.

\section{Materials and Methods}

\subsection{Target Site Selection and In Vitro Cleavage Assay}

The Zea mays IPK gene sequence data was obtained from the NCBI GenBank (accession B73RefGen_v3). In vitro tests were performed to confirm the RNP complex efficiency to cleave target DNA. The target site was amplified using specific primers. The crispr-RNAs (crRNAs) were designed for the third exon of the IPK gene in maize using the platform CRISPR-Cas9 guide RNA Design Checker (Integrated DNA Technologies Inc. IDT, Coralville, IA, SUA). Commercially available Cas9 protein (160 kDa) was also purchased from IDT (Table 1).

Table 1. List of primers and crispr-RNAs (crRNAs) used for the amplification and mutation of the inositol phosphate kinase gene (IPK) target locus in maize via CRISPR (Clustered Regularly Interspaced Short Palindromic Repeats)-Cas9.

\begin{tabular}{ccc}
\hline Primer & Sequence $\left(\mathbf{5}^{\prime} \mathbf{3}^{\prime} \mathbf{)}\right.$ & Amplicon Size (bp) \\
\hline ZmIPK-F & GAAGAAGCAGCAGAGCTTCA & 876 \\
ZmIPK-R & CAGAAGAAATCCGTGAGGACAG & \\
\hline crRNA & Sequence $\left(\mathbf{5}^{\prime} \mathbf{3}^{\prime} \mathbf{)}\right.$ & Cleavage Fragments (bp) \\
\hline crRNA1 & AGCTCGACCACGCCGCCGAC & $279 \mid 597$ \\
crRNA2 $^{*}$ & GGGATCCGTCTCCTTCTCCC & $617 \mid 259$ \\
crRNA3 & ATCTTCAAGGTCTACGTCGT & $525 \mid 351$ \\
crRNA4 * & CAGGAGTTCGTCAACCATGG & $498 \mid 378$ \\
crRNA5 & ACAAGCTCTACGGAGACGAC & $141 \mid 735$ \\
\hline
\end{tabular}

gRNA, crRNA (100 nM), and trans-activating crispr-RNA (tracrRNA) (100 nM) were incubated for 5 min at $95^{\circ} \mathrm{C}$, according to the manufacturer's instructions. Cas $9(100 \mathrm{nM})$, gRNA, and $1 \times$ NEBuffer 3 (New England Biolabs Inc, NEB) were incubated for $10 \mathrm{~min}$ at $25^{\circ} \mathrm{C}$ to form the RNP complex. Amplified PCR products ( $300 \mathrm{ng}$ ) were then incubated for $60 \mathrm{~min}$ at $37^{\circ} \mathrm{C}$ with the RNP complex. Proteinase K $(800 \mathrm{U} / \mathrm{mL})$ was added to stop the reaction. The products were visualized using $1 \%$ agarose gel electrophoresis [13].

\subsection{Maize Protoplast Isolation and Fluorescent Transfection Assay}

Mesophyll protoplasts were isolated following the protocol described by Sheen et al. [21] with some modifications. Etiolated maize seedlings were grown in vermiculite after disinfestation of the seeds with $70 \%$ alcohol $(60 \mathrm{~s}$ ), $\mathrm{NaOCl} \%$ (twice of $15 \mathrm{~min}$ ), and triple washing with sterile water. 
Ten-days-old seedlings were used (three days under $16 \mathrm{~h}$ light/day and seven days in darkness). The middle portion of the second leaves were cut into thin strips $(0.5-1 \mathrm{~mm})$, and immersed in a cell-wall digestion enzyme solution ( $0.3 \%$ macerozyme R-10, $1.5 \%$ cellulase R-10, $10 \mathrm{mM}$ of MES pH 5.7, $0.6 \mathrm{M}$ mannitol, $10 \mathrm{mM} \mathrm{CaCl}_{2}, 5 \mathrm{mM}$ ß-mercapto, $0.1 \% \mathrm{BSA}$ ). The material was left in a vacuum for $30 \mathrm{~min}$ and gentle shaking at $40 \mathrm{rpm}$ in the dark for $4 \mathrm{~h}$. The protoplasts were released thoroughly by shaking at $80 \mathrm{rpm}$ for $5 \mathrm{~min}$ After digestion, the protoplasts were diluted with the same volume of cold W5 solution [2 mM MES (pH 5.7), $154 \mathrm{mM} \mathrm{NaCl}, 125 \mathrm{mM} \mathrm{CaCl}_{2}, 5 \mathrm{mM} \mathrm{KCl}$ ] and filtered through a double filter (14 and $40 \mu \mathrm{M}$ Nylon mesh). Protoplasts were collected after centrifugation at $100 \mathrm{~g}$ for $3 \mathrm{~min}$ and washed two times in $10 \mathrm{~mL}$ of W5 solution. Protoplasts were resuspended in cold MMG solution [0.4 M mannitol, $4 \mathrm{mM}$ MES ( $\mathrm{pH} 5.7), 15 \mathrm{mM} \mathrm{MgCl}_{2}$ ]. Its viability and concentration were determined using Fluorescein Diacetate (FDA; $0.2 \%$ ) dye in the hemocytometer. To confirm the internalization of the RNP complex inside cells, an assay was performed using fluorescent-labeled tracrRNA molecules (ATTO 550, IDT) [9]. Microphotographs were taken using an inverted optic microscope ix80 Olympus.

\subsection{Maize Protoplast Transformation}

Maize protoplasts were gene-edited by introducing CRISPR-Cas9 RNP complex (no integration of exogenous DNA) via PEG-mediated transfection (Figure 1). Protoplast transformation was adapted from Woo et al. [12] and Malnoy et al. [13]. First, $15 \mu \mathrm{g}$ of the two components of the gRNA (crRNA and trans-activating crispr RNA-tracrRNA)) were incubated at $95^{\circ} \mathrm{C}$ for $5 \mathrm{~min}$. After allowing them to cool at room temperature, $45 \mu \mathrm{g}$ of Cas 9 and $1 \times$ NEBuffer 3 were added, then mixed, and incubated at $25^{\circ} \mathrm{C}$ for $10 \mathrm{~min}$. Finally, the RNP complex was mixed with $100 \mu \mathrm{L}$ of protoplasts $\left(1 \times 10^{5}\right.$ protoplasts), $250 \mu \mathrm{L}$ of PEG solution (40\% PEG 4000, $0.2 \mathrm{M}$ mannitol, $\left.0.1 \mathrm{M} \mathrm{CaCl}_{2}\right)(\mathrm{pH} 6.0)$, and incubated at $25^{\circ} \mathrm{C}$ in the dark. Two incubation times were tested: $\mathrm{T} 1=20 \mathrm{~min}$ and $\mathrm{T} 2=40 \mathrm{~min}$ W5 solution (950 ul) was added and the tubes were centrifuged at $100 \mathrm{~g}$ for $3 \mathrm{~min}$. Protoplasts were resuspended in $1 \mathrm{~mL} \mathrm{W1}$ solution [4 mM MES (pH 5.7), $0.5 \mathrm{M}$ mannitol, $20 \mathrm{mM} \mathrm{KCl}$ ], and then transferred to multi-well plates for $24 \mathrm{~h}$ under gentle agitation ( $40 \mathrm{rpm})$ in the dark at $25^{\circ} \mathrm{C}$.

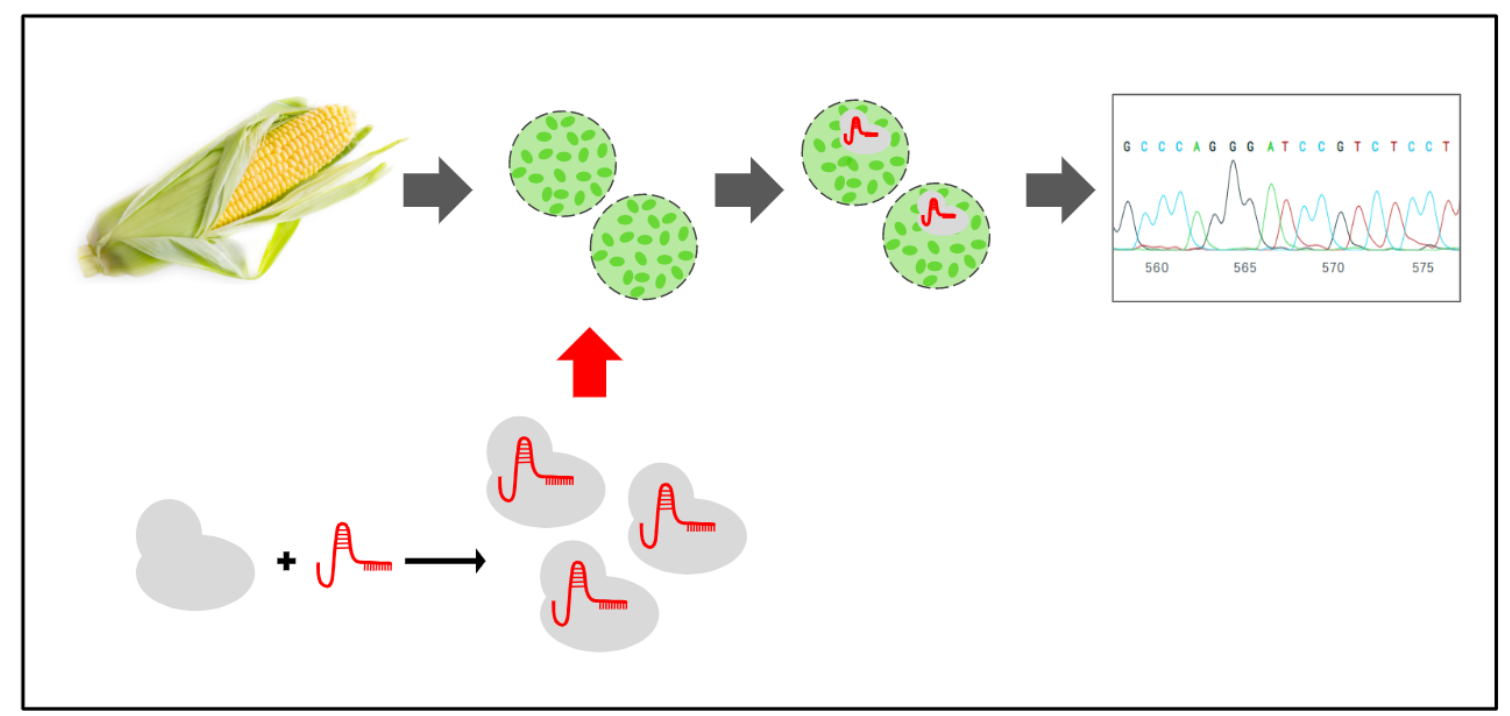

Figure 1. Methodological approach of the present study. Maize seeds were germinated in vitro; the second leaves of the seedlings were used to obtain the protoplasts. The protoplasts were exposed to the CRISPR-Cas9 ribonucleoproteins complex (RNP), and after $24 \mathrm{~h}$, the DNA was extracted from the samples. PCR fragments were amplified and sequenced. Maize image was taken from the free repository from pexel.com. 


\subsection{Gene-Editing Efficiency Analysis by Sanger Sequencing}

In order to characterize the spectrum and frequency of DNA changes at the target gene, genomic DNA was isolated using DNeasy ${ }^{\circledR}$ Plant Mini Kit (QIAGEN ${ }^{\circledR}$ Biotecnologia Brasil Ltd., Sao Paulo, SP, Brazil), followed by amplification of the target region by PCR using Taq Q5 High-Fidelity DNA Polymerase (NEB ${ }^{\circledR}$, Ipswich, MA, USA) and primers listed in Table 1. PCR samples were purified and sequenced using the BigDye Terminator 3.1v Kit (ThermoFisher Scientific, Sao Paulo, SP, Brazil). Samples were resuspended in formamide, denatured at $95^{\circ} \mathrm{C}$ for $5 \mathrm{~min}$, and incubated on ice for $3 \mathrm{~min}$. Sequencing was performed using the Sanger [22] automated sequencer from the 3500xL Dx Genetic Analyzer for Sequencing (Applied Biosystems ${ }^{\mathrm{TM}}$-ThermoFisher Scientific, Sao Paulo, SP, Brazil).

CRISPR-Cas9 DNA changes were calculated based on the insertions and deletions (In/Dels) around the cleavage site ( $3 \mathrm{bp}$ upstream of the PAM sequence) using the Inference of CRISPR Editing Software-ICE software v.2 (Synthego Corporation, Palo Alto, CA, USA). It has been previously shown that the ICE software results are comparable to the Next Generation Sequencing (NGS) results [23].

\section{Results}

\subsection{In Vitro Cleavage Assay}

Cleavage activity of gRNAs 1 to 5 was tested using $0.5 \mu \mathrm{g}$ of crRNA and $1.5 \mu \mathrm{g}$ of Cas9 enzyme to $300 \mathrm{ng}$ of DNA. While all the designed gRNAs were able to cleave PCR products of the IPK gene in our study, the different gRNA sequences varied in their cleavage efficiency (Figure 2). gRNA2, 3, and 4 showed the highest activity and were, therefore, chosen for subsequent experiments on the transfection of maize protoplasts.

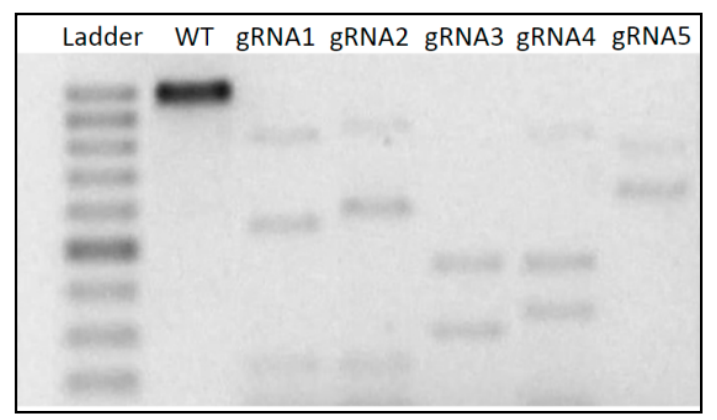

Figure 2. Schematic diagram of the Maize IPK gene locus with the guide RNAs (gRNAs) target sites. The in vitro CRISPR-Cas9 assay showing the original and the cleaved fragments of the IPK gene in maize that were submitted to the RNP complex with the crRNA1, 2, 3, 4, and 5. Note: WT = Wild Type (control).

\subsection{Targeted Mutagenesis in Maize Using CRISPR-Cas9 Ribonucleoproteins}

Protoplasts viability was checked before and $1 \mathrm{~h}$ after transformation. The viability of protoplasts at the isolation step was on average $75 \%$ and on average more than $65 \%$ after transformation. Therefore, these protoplasts were considered stable after transformation, which would allow further cell culture propagation.

Frequently, results indicating low efficiency of CRISPR-Cas9 editing using RNPs delivery cannot discriminate low transfection rates from poor DNA cleavage and repair activity. In order to overcome this limitation and confirm the internalization of Cas9-gRNA RNPs, we performed a fluorescent microscopy assay. Labeled tracrRNA molecules confirmed the internalization of the RNP complex (Figure 3). Although this is not a quantitative method, it showed that at least one-third of the labeled molecules were internalized. 


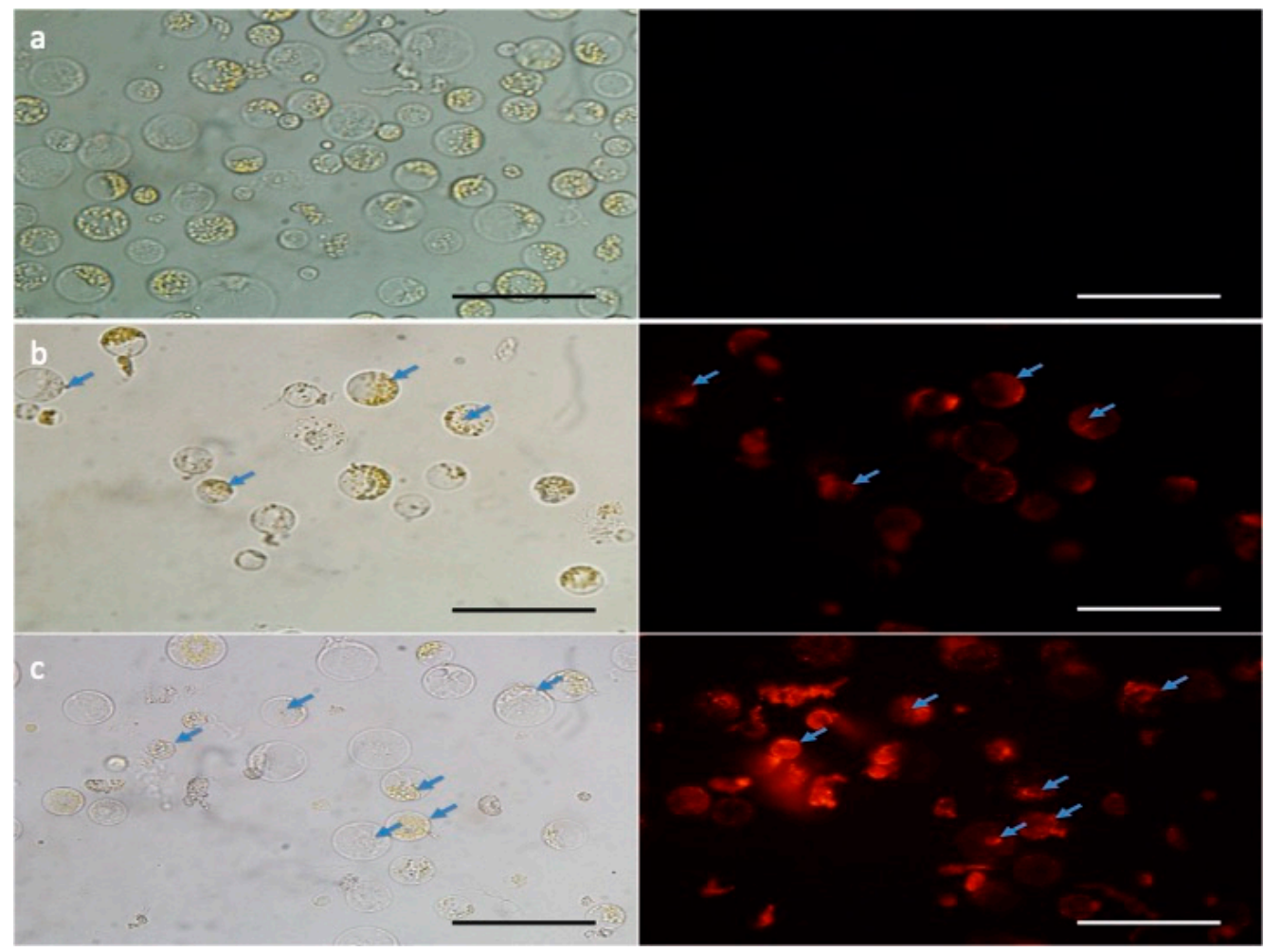

Figure 3. Microscope photographs of maize protoplast cells transfected with polyethylene glycol (PEG)-mediated CRSIPR-Cas9 RNP. The RNP containing the ATTO550-conjugated trans-activating crispr RNA (tracrRNA) was transfected into maize protoplasts and cells were monitored under fluorescent microscopy to check the transfection efficiency. Comparing to the cells without CRISPR-Cas9 delivery (a-control sample), the red fluorescent signal was detected in CRISPR-Cas9 treated samples (b and c-right). Photographs were taken with white light (left side) and fluorescent light (right side). Blue arrows indicate the internalization of the RNP complex. Scale bars: $100 \mu \mathrm{m}$.

RNPs containing gRNAs 2, 3, and 4 were transfected into isolated protoplasts with PEG 4000 and the results are displayed as the percentage of indels detected at the cleavage site based on Sanger sequencing and analysis with the ICE software v.2 (Figure 4). The concentration of 45 ug of Cas9 and $15 \mathrm{ug}$ of gRNA to $100 \mathrm{ul}$ protoplasts in a 3:1 ratio resulted in the best cost-efficiency correlation. This result is also in agreement with previous reports on RNPs delivery into protoplasts, which ranged from 30-60 ug of Cas9 in a 1:1 and 3:1 ratio [12,13,24]. Exposure time was tested for all three gRNA sequences in 20- and 40-min of exposure. While a longer exposure time to the RNP complex led to a higher mutation index for all gRNAs tested, the increase in mutation rate was not consistent among all gRNA sequences (approx. seven-fold, three-fold, and one-fold for the gRNAs 2, 3, and 4, respectively). Deletions were shown more frequent than insertions in this model system. A higher insertion rate was only observed for gRNA 2 at 40 min time of exposure.

DNA sequences from the universal primer used to amplify the IPK gene in maize ( $876 \mathrm{bp}$ ) from treated samples were compared to the same fragment in negative controls (no RNP delivered). Other negative controls (Cas9 or gRNAs delivered alone) were also tested against the first negative control and showed no DNA changes. The obtained gene-edited sequences for each gRNA at 40 min of exposure are displayed in Figure 5. About six sequence variants were of major contribution in gene-editing efficiency for the three selected gRNA sequences.

Results on the percentage of mutated sequences (technology efficiency), the size of the DNA change (number of base pair change), the type of DNA change (deletions or insertions), and a theoretical knockout $(\mathrm{KO})$ score are summarized in Table 2. The indel percentage at $20 \mathrm{~min}$ of exposure was, on average, $1.63 \%$ in contrast to $4.37 \%$ at 40 min-exposure time. Overall, gRNA 4 was most efficient and 
consistent at both exposure time. Intriguingly, gRNA 2 showed the lowest efficiency at $20 \mathrm{~min}(0.85 \%)$ but the highest efficiency at $40 \mathrm{~min}(5.85 \%)$. The Knockout Score accounts for the reads containing an amino acid frameshift change or $21+\mathrm{bp}$ indel. Thus, indicating the contributing indels that are likely to result in a functional knockout of the targeted gene. In the present study, the KO score was, on average, $0.83 \%$ for the $20 \mathrm{~min}$ and $3.17 \%$ for the $40 \mathrm{~min}$ of exposure treatment, which suggests that the majority of indels were frameshift modifications. In addition, only one gRNA at one time point presented a single base pair change as the most frequent mutation (gRNA 2 with a -1 bp). Notably, a deletion of $19 \mathrm{bp}$ was the most abundant DNA change for gRNA 3 (0.9\%). Moreover, all other gRNAs and exposure times showed a 2 bp deletion as the most frequent DNA change. Overall, the DNA change ranged from $-28 \mathrm{bp}$ to $+12 \mathrm{bp}$ change.

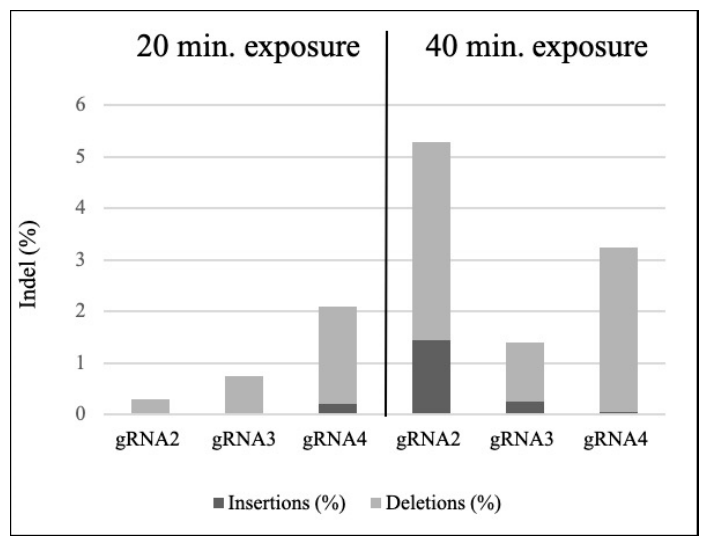

Figure 4. Frequency of mutations in maize protoplasts generated by CRISPR-Cas9 and measured by the Inference of CRISPR Editing Software-ICE software v.2. Different gRNAs and exposure time of the protoplasts to the RNP complex are represented. Percentages of insertions and deletions are represented in dark grey and light grey, respectively.

Table 2. Mutation rates in Zea mays IPK gene target region produced by CRISPR-Cas RNP delivery and analyzed by Sanger sequencing and ICE software analysis.

\begin{tabular}{ccccccc}
\hline Sample & $\begin{array}{c}\text { Incubation } \\
\text { Time (min) }\end{array}$ & \% of Indel & $\begin{array}{c}\text { Model Fit } \\
\mathbf{( R}^{\mathbf{2}}\end{array}$ & $\begin{array}{c}\text { KO } \\
\text { Score }\end{array}$ & $\begin{array}{c}\text { Mutation } \\
\text { Range (bp) }\end{array}$ & $\begin{array}{c}\text { Greater } \\
\text { Contribution } \\
\text { (bp) }\end{array}$ \\
\hline Cas9 only & 20 & 0 & & 0 & 0 & 0 \\
gRNA2 only & 20 & 0 & & 0 & 0 & 0 \\
gRNA3 only & 20 & 0 & & 0 & 0 & 0 \\
gRNA4 only & 20 & 0 & & 0 & 0 & 0 \\
Cas9 + gRNA2 rep1 & 20 & 0 & 0.99 & 0 & 0 & -2 \\
Cas9 + gRNA2 rep2 & 20 & 1 & 1 & 1 & -4 to -2 & -2 \\
Cas9 + gRNA3 rep1 & 20 & 0 & 1 & 0 & -7 to -1 & -2 \\
Cas9 + gRNA3 rep2 & 20 & 1 & 1 & 1 & -7 to -1 & -2 \\
Cas9 + gRNA4 rep1 & 20 & 3 & 0.99 & 2 & -7 to +12 & -2 \\
Cas9 + gRNA4 rep2 & 20 & 1 & 0.99 & 1 & -2 to +3 & -1 \\
Cas9 + gRNA2 rep1 & 40 & 4 & 0.99 & 4 & -7 to +1 & -1 \\
Cas9 + gRNA2 rep2 & 40 & 6 & 1 & 6 & -8 to +1 & -1 \\
Cas9 + gRNA3 rep1 & 40 & 1 & 1 & 1 & -19 to -1 & -19 \\
Cas9 + gRNA3 rep2 & 40 & 2 & 0.96 & 2 & -28 to +8 & -2 \\
Cas9 + gRNA4 rep1 & 40 & 2 & 0.99 & 2 & -3 to -2 & -2 \\
Cas9 + gRNA4 rep2 & 40 & 5 & 1 & 4 & -16 to +12 & -2 \\
\hline
\end{tabular}

Note: $\mathrm{KO}=$ Knockout. 


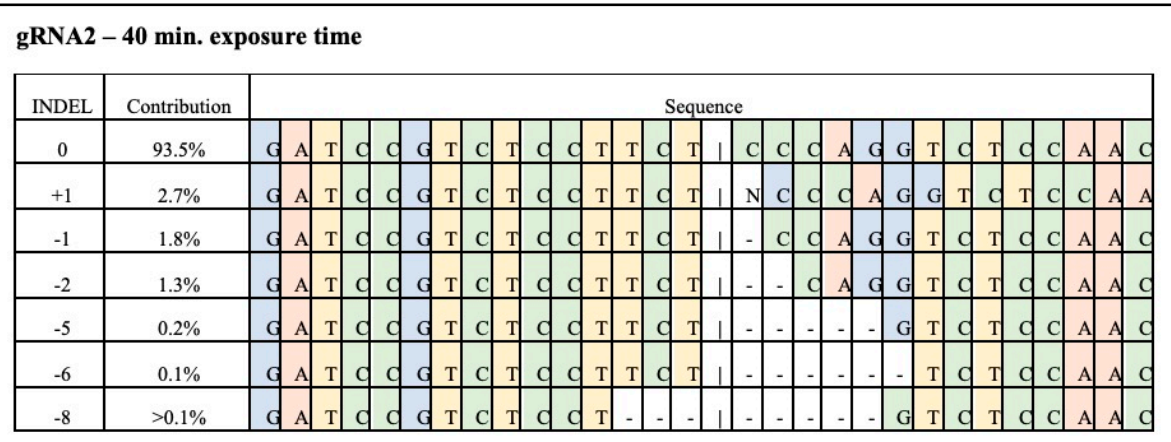

gRNA3 - 40 min. exposure time

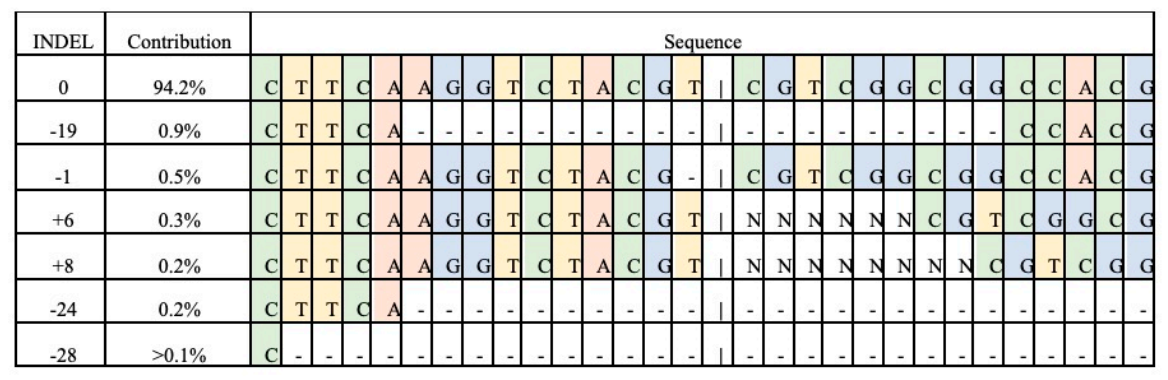

gRNA4 - 40 min. exposure time

\begin{tabular}{|c|c|c|c|c|c|c|c|c|c|c|c|c|c|c|c|c|c|c|c|c|c|c|c|c|c|c|}
\hline INDEL & Contribution & \multicolumn{25}{|c|}{ Sequence } \\
\hline 0 & $95 \%$ & d c & $\mathrm{A}$ & & $\mathrm{T}$ & $\mathrm{T}$ & c & \begin{tabular}{l|l}
$\mathrm{G}$ & $\mathrm{T}$
\end{tabular} & $\mathrm{T} d$ & A & A & c & d & A & $\mathrm{T}$ & $\mathrm{G}$ & d & d & d G & $\mathrm{C}$ & d & $\mathrm{T}$ & $\mathrm{d} A$ & $\mathrm{~T}$ & & $T$ \\
\hline-2 & $3.3 \%$ & d $\mathrm{c}$ & $\mathrm{A}$ & c & $\mathrm{T}$ & $\mathrm{T}$ & c & \begin{tabular}{l|l}
$\mathrm{G}$ & $\mathrm{T}$ \\
$\mathrm{T}$
\end{tabular} & d & & A & c & - & 1 & $\mathrm{~T}$ & $\mathrm{G}$ & d & d & d G & C & d & c & d A & $\mathrm{T}$ & & $\mathrm{T}$ \\
\hline-3 & $0.8 \%$ & d c & $A$ & ( & $\mathrm{T}$ & $\mathrm{T}$ & c & \begin{tabular}{l|l}
$\mathrm{G}$ & $\mathrm{T}$ \\
$\mathrm{T}$
\end{tabular} & $\mathrm{I} \mathrm{d}$ & & $\mathrm{A}$ & - & - & - & $\mathrm{T}$ & $\mathrm{G}$ & d & d & d G & c & d & $\mathrm{T}$ & $\mathrm{d} A$ & $\mathrm{~T}$ & & $\mathrm{~T}$ \\
\hline-1 & $0.4 \%$ & d c & $A$ & c & $\mathrm{T}$ & $\mathrm{T}$ & c & \begin{tabular}{l|l}
$\mathrm{G}$ & $\mathrm{T}$ \\
$\mathrm{C}$
\end{tabular} & I d & & A & c & d & & $\mathrm{T}$ & G & d & d & d G & c & d & $\mathrm{T}$ & d A & $\mathrm{T}$ & & $\mathrm{T}$ \\
\hline-7 & $0.1 \%$ & d c & $\mathrm{A}$ & 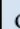 & $\mathrm{T}$ & $\mathrm{T}$ & C & \begin{tabular}{l|l}
$\mathrm{G}$ & $\mathrm{T}$
\end{tabular} & $\mathrm{T} d$ & & A & - & -1 & 1 & - & - & -1 & -1 & $\mathrm{~d} \mathrm{G}$ & c & d & c & $\mathrm{A}$ & $\mathrm{T}$ & & $T$ \\
\hline+12 & $0.1 \%$ & d $\mathrm{c}$ & $A$ & & T) & $\mathrm{T}$ & C & \begin{tabular}{l|l}
$\mathrm{G}$ & $\mathrm{T}$ \\
$\mathrm{C}$
\end{tabular} & T & & A & C & d & A & $\mathrm{N}$ & $\mathrm{N}$ & $N$ & $\mathrm{~N}$ & $\mathrm{~N}$ & $\mathrm{~N}$ & $N$ & & $\mathrm{~N}$ & $\mathrm{~N}$ & & $\mathrm{G}$ \\
\hline-1 & $0.1 \%$ & d c & $A$ & & $\mathrm{~T}$ & $\mathrm{~T}$ & C & \begin{tabular}{l|l}
$\mathrm{G}$ & $\mathrm{T}$
\end{tabular} & T d & & A & C & d & A & - & $\mathrm{G}$ & $\mathrm{d}$ & $\mathrm{d}$ & d G & C & d & & $\mathrm{d}$ A & $\mathrm{T}$ & & $T$ \\
\hline-16 & $>0.1 \%$ & d c & $\mathrm{G} /$ & & 10 & $\mathrm{~T}$ & C & \begin{tabular}{l|l}
$\mathrm{G}$ & $\mathrm{T}$
\end{tabular} & $\mathrm{T} d$ & $\mathrm{~A}$ & A & & & 1 & - & & & & - & & & & & & & \\
\hline
\end{tabular}

Figure 5. Sequence distribution of most efficient mutations identified with the ICE software around the IPK gene target site in Zea mays. Edited sequences were obtained after CRISPR-Cas9 RNP transfection to maize protoplasts. Forty-five $\mu \mathrm{g}$ of Cas9 preassembled with $15 \mu \mathrm{g}$ of each gRNA were used in the protoplast transformation. Different exposure times of the RNP complex with the protoplast are presented. Cut sites are represented by black vertical dotted lines, insertions are represented by ' $\mathrm{N}$ ' and deletions by black horizontal dotted lines.

\section{Discussion}

CRISPR-Cas9 technology is a powerful tool for plant breeding and research. While still evolving as a technology to determine the rules for gRNA design and the algorithms to predict target and 'off-target' sequences, CRISPR applications still rely on empirical results to test the performance of new systems [25]. Notably, gene-editing results outcomes are frequently species-dependent [26]. Therefore, a CRISPR platform for different species with a rapid and efficient evaluation protocol is needed before commercialization.

Our experiments demonstrated the suitability of the PEG-delivered CRISPR-Cas9 RNPs system for gene-editing screening in maize. We showed that high-efficiency gene-edited maize cells could be obtained using less time-consuming ( 15 days) and labor-intensive procedures (PCR, agarose gel electrophoresis, and Sanger sequencing). In addition, the advantage of our system in relation to the use of vectors is that it prevents the integration and expression of exogenous DNA sequences, isolating 
the effect of gene-editing modification and avoiding transgene-introgressed side effects. Although non-integrating plasmids could be transfected into plant cells to deliver programmable nucleases, transfected plasmids are degraded in cells by endogenous nucleases, and the resulting small DNA fragments can be inserted at both on-target and off-target sites in host cells (Kim et al. 2014) [27]. For example, Braatz et al. [28] performed whole-genome sequencing after the transfection of the expression construct CRISPR-Cas9 in Brassica napus and found that the transformation resulted in at least five independent insertions of the vector backbone sequences in the plant genome.

\subsection{Ribonucleoprotein Delivery in Plants}

In the present report, we show a positive correlation between the time of exposure to RNPs and the efficiency of site-directed mutagenesis in maize, as ascertained with Sanger sequencing. In previous reports referring to the use of RNPs in plant protoplasts (Table 3), the authors used one or more different concentrations of RNPs and Cas9:gRNA ratios, but the effect of exposure time on mutation frequencies was not tested [29,30]. CRISPR RNPs were delivered to apple, grapevine, brassica sp., lettuce, tobacco, and rice plants at less or equal than 20 min exposure time and their efficiencies ranged between 0.1 and $40 \%[12,13,31]$. In petunia and wheat protoplasts exposure for 30 min granted 0.2 up to $45 \%$ efficiency [14,17]; thus, suggesting that time of exposure might not alone explain indel frequency in different plant systems. In our system, when all other factors are maintained, exposure time consistently increased indel frequency for all three gRNA sequences tested (up to approx. seven-fold change increase).

The Cas9:gRNA ratio also influences target efficiency in a species-specific manner. Three different Cas9:gRNA ratios were tested in apple and grapevine protoplasts [13]. While the 1:1, 1:3, and 3:1 ratios did not differ in mutation frequency for grapevine $(0.1 \%)$, the $1: 1$ and 3:1 ratios increased indel frequency in two (6.6 and 2.6 fold change respectively) out of three gRNA sequences in apple. Overall, the results obtained for the 3:1 ratio are equivalent to our results applying the same ratio (from 3.3\% up to $6.7 \%$ efficiency). Cas9 concentration has been shown to be of major factor influencing the delivery of RNPs to plant cells. Woo et al. [12] tested 20 and 60 ug of Cas9 to Arabidopsis protoplasts and found that the editing efficiency was not directly related to the Cas 9 concentration but also dependent on the time course of the analysis. At $24 \mathrm{~h}$ after delivery, more efficiency was observed when applying 20 instead of $60 \mathrm{ug}$ of Cas9 (71 in contrast to 54\%). Opposite results were obtained at $72 \mathrm{~h}$ after delivery. Nevertheless, increasing the amount of Cas9 $(7.5,15.30$, and $60 \mathrm{ug})$ was consistent with a crescent indel frequency in brassica sp. protoplasts [31]. The efficiency results obtained in our study were similar to those obtained applying approximately 60-90 ug of Cas9, thus, indicating that a lower amount of Cas9 (45 ug) but a higher exposure time (40 min) might have similar cleavage levels. Overall, it is clear that the limited amount of studies investigating the RNP delivery into plant cells is insufficient to draw definitive conclusions for increasing gene-editing efficiency using this system.

Table 3. Publications with DNA-free gene editing in plants using CRISPR-Cas9 RNPs and other delivery methods for maize.

\begin{tabular}{|c|c|c|c|c|}
\hline Reference & Plant Species & Plant Material & Transfection Method & $\begin{array}{l}\text { Gene-Editing } \\
\text { Efficiency }\end{array}$ \\
\hline \multicolumn{5}{|c|}{ RNP delivered in plants } \\
\hline$[12]$ & $\begin{array}{c}\text { Arabidopsis thaliana, Lactuca } \\
\text { sativa, Nicotiana attenuata, } \\
\text { Oryza sativa }\end{array}$ & Protoplasts & PEG-mediated & $5.7-40.0 \%$ \\
\hline [13] & Malus domestica, Vitis vinifera & Protoplasts & PEG-mediated & $0.1-6.9 \%$ \\
\hline [14] & Petunia $x$ hybrid & Protoplasts & PEG-mediated & $2.4-21.0 \%$ \\
\hline$[31]$ & Triticum aestivum & $\begin{array}{c}\text { Protoplasts, } \\
\text { immature embryos }\end{array}$ & PEG-mediated, Biolistics & $0.2-45.3 \%$ \\
\hline [15] & Solanum tuberosum & Protoplasts & PEG-mediated & $1.0-25.0 \%$ \\
\hline [32] & Brassica oleracea, Brassica rapa & Protoplasts & PEG-mediated & $0.1-24.5 \%$ \\
\hline$[33]$ & Oryza sativa & Zygotes & PEG-mediated & $14.0-64.0 \%$ \\
\hline
\end{tabular}


Table 3. Cont.

\begin{tabular}{|c|c|c|c|c|}
\hline Reference & Plant Species & Plant Material & Transfection Method & $\begin{array}{l}\text { Gene-Editing } \\
\text { Efficiency }\end{array}$ \\
\hline \multicolumn{5}{|c|}{ Other delivery methods in maize } \\
\hline \multirow[t]{2}{*}{ [34] } & Zea mays & Protoplasts & Vector via PEG-mediated & $13.1 \%$ \\
\hline & & Immature embryos & Agrobacterium-mediated & $16.4-19.1 \%$ \\
\hline [35] & Zea mays & Protoplasts & Vector via PEG-mediated & N.A \\
\hline [24] & Zea mays & Immature embryos & Vector via biolistics & $1.3-4.6 \%$ \\
\hline [17] & Zea mays & Protoplasts & Vector via biolistics & $80.0-90.0 \%$ \\
\hline [36] & Zea mays & Immature embryos & Agrobacterium-mediated & $57.1-71.4 \%$ \\
\hline \multirow[t]{2}{*}{ [19] } & Zea mays & Protoplasts & Vector via PEG-mediated & $2.8-27.0 \%$ \\
\hline & & Immature embryos & Agrobacterium-mediated & $19.0-31.0 \%$ \\
\hline \multirow[t]{2}{*}{ [37] } & Zea mays & Protoplasts & Vector via PEG-mediated & $4.0-11.9 \%$ \\
\hline & & Immature embryos & Agrobacterium-mediated & $65.8-86.9 \%$ \\
\hline [16] & Zea mays & Immature embryos & RNP via Biolistics & $0.01-0.7 \%$ \\
\hline [18] & Zea mays & Immature embryos & Agrobacterium-mediated & $12.0-74.0 \%$ \\
\hline [38] & Zea mays & Immature embryos & Vector via Biolistics & $60.0-98.0 \%$ \\
\hline [39] & Zea mays & Immature embryos & Agrobacterium-mediated & N.A \\
\hline [19] & Zea mays & Immature embryos & Agrobacterium-mediated & $5.0-100 \%$ \\
\hline [20] & Zea mays & Immature embryos & Agrobacterium-mediated & N.A \\
\hline [40] & Zea mays & Immature embryos & Agrobacterium-mediated & $90.0-100 \%$ \\
\hline [41] & Zea mays & Immature embryos & Agrobacterium-mediated & N.A \\
\hline [42] & Zea mays & Immature embryos & Agrobacterium-mediated & N.A \\
\hline [43] & Zea mays & Immature embryos & Agrobacterium-mediated & N.A \\
\hline [44] & Zea mays & Immature embryos & Agrobacterium-mediated & N.A \\
\hline [45] & Zea mays & Immature embryos & Agrobacterium-mediated & N.A \\
\hline [46] & Zea mays & Immature embryos & Vector via biolistics & N.A \\
\hline [47] & Zea mays & Immature embryos & Agrobacterium-mediated & $25.0-100 \%$ \\
\hline [48] & Zea mays & Immature embryos & Agrobacterium-mediated & N.A \\
\hline $\begin{array}{l}\text { Present } \\
\text { study }\end{array}$ & Zea mays & Protoplasts & RNA via PEG-mediated & $0.85-5.85 \%$ \\
\hline
\end{tabular}

Note: N.A is 'not applicable' because transgenic plants were either selected using antibiotic marker genes or the analysis was not performed.

\subsection{CRISPR Delivery Methods in Maize}

Other delivery methods have been tested for maize as screening methods or gene-editing breeding methods, and these include PEG-mediated vector transfection, Agrobacterium-mediated, and biolistics (Table 3). The vast majority of studies still rely on vector-based transformation delivery of CRISPR. None of the listed studies have provided a cell-based screening method without the insertion of foreign vector-based DNA. On average, PEG-mediated vector transfection reached an average of about 12\% efficiency, whereas Agrobacterium and biolistics reached $44 \%$ and $83 \%$, respectively. In addition, most of these methods used embryogenic callus as explant material. Callus-based methods harbor chimeric tissues, thus, requiring subsequent genetic fixation to allow the stable inheritance of the edited traits. Therefore, these are not suitable material for genetic screening of successful gene-edited plants. Currently, many protocols are available for regeneration of whole plants from protoplasts. These include lettuce, tobacco, and rice, petunia, wheat, apple, and soybean. It is also suggested as a future choice for gene-edited maize and the list seems to expand because of the capabilities of the RNP technology $[16,49]$. The trade-off in efficiency percentage plays in return for avoiding unintended DNA integration and the potential undesirable biosafety risks.

\subsection{Analytical Platforms for Gene-Editing Detection}

Different analytical platforms for the detection and identification of CRISPR outcomes are reflected in frequency results as they show different analytical sensitivity. Woo et al. [12] showed a $40 \%$ transformation efficiency in tobacco when samples were analyzed by the Illumina sequencing platform. In contrast, the same samples showed a much lower efficiency rate $(17 \%)$ when analyzed by the T7 cleavage assay. While T7 cleavage assays are nowadays being limited to a qualitative rather than 
quantitative detection methods, high-throughput sequencing platforms are time-consuming and costly options for screening protocols. Usually, such platforms are available in other labs or through service providers, which require long processing time and high costs for samples and assays that are still at the screening stage. In order to overcome such problems, we have proposed a model that analyzes gene-edited cell pools using data from common Sanger sequencing analysis. More specifically, we use the ICE: Inference of CRISPR Edits software, which enable the analysis of mixed populations and strongly correlates with next-generation sequencing of amplicons using Sanger sequencing data [23].

However, the proposed model is focused on providing a simple, cost-efficient analysis of gene-editing outcomes at the screening stage. The model is currently limited to detect mutations with more than $30 \mathrm{bp}$ deletions or more than $14 \mathrm{bp}$ additions. The analysis also does not account for very small mutant populations $(<0.1 \%)$ neither presents mutations with a substitution of bp [23]. Although our platform does not apply exogenous DNA generating potential integration, it cannot be ruled out that microhomologies with gRNA sequences produce spurious cleavage or larges genomic rearrangements [50]. Therefore, long-run high throughput sequencing analysis is recommended for follow up breeding programs and safety tests [51].

\section{Conclusions}

We have shown that RNPs could be used for targeted CRISPR-Cas9 via PEG delivery as a model system to screen for gene-editing outcomes in maize. Target insertion and deletion DNA changes (In/Dels) were induced using 45 ug of Cas9 and gRNA used at a 3:1 ratio, and a positive correlation between exposure time (20 and $40 \mathrm{~min}$ ) and indel frequency was observed. By targeting preserved coding regions, we can anticipate that the model could be applied to several maize varieties by validation using IPK gene. However, in vivo In/Del frequencies differed among gRNA sequences. In addition, the proposed method for sequencing analysis is also restricted to a window of $30 \mathrm{bp}$ deletions and 14 bp additions. Further studies will be focused on CRISPR-Cas9 off-target activity and on the regeneration of edited protoplasts.

Author Contributions: Conceptualization, R.O.N. and S.Z.A.-T.; Methodology, R.R.A.S., C.A.C. and S.Z.A.-T.; Software, R.R.A.S.; Validation, R.R.A.S. and C.A.C.; Formal Analysis, R.R.A.S., C.A.C. R.O.N. and S.Z.A.-T.; Investigation, R.R.A.S., C.A.C. and S.Z.A.-T.; Resources, R.O.N. and S.Z.A.-T.; Data Curation, R.R.A.S. and S.Z.A.-T.; Writing-Original Draft Preparation, R.R.A.S. and S.Z.A.; Writing-Review \& Editing, R.R.A.S., C.A.C. R.O.N. and S.Z.A.-T.; Visualization, R.R.A.S. and S.Z.A.; Supervision, R.O.N. and S.Z.A.-T.; Project Administration, S.Z.A.-T.; Funding Acquisition, S.Z.A.-T. All authors have read and agreed to the published version of the manuscript.

Funding: This research was funded by GenØk Centre for Biosafety through its funds from The Ministry of Climate and Environment in Norway. Scholarship from National Council for Scientific and Technological Development (CNPq) was provided to R.R.A.S. and R.O.N.

Acknowledgments: We would like to thank Lilian Machado (UFSC) for taking care of the Sanger sequencing. The authors are also grateful to Vinicius Vilperte for insightful comments and suggestions on the sequencing analysis and also to Miguel Guerra for his support in using his laboratory. This work was financed by GenØk Centre for Biosafety through its funds from The Ministry of Climate and Environment in Norway, whose support is gratefully acknowledged.

Conflicts of Interest: The authors declare no conflict of interest.

\section{References}

1. Jinek, M.; Chylinski, K.; Fonfara, I.; Hauer, M.; Doudna, J.A.; Charpentier, E. A programmable dual-RNA-guided DNA endonuclease in adaptive bacterial immunity. Science 2012, 337, 816-821. [CrossRef] [PubMed]

2. Hsu, P.D.; Scott, D.; Weinstein, J.A.; Ran, F.A.; Konermann, S.; Agarwala, V.; Li, Y.; Fine, E.J.; Wu, X.; Shalem, O.; et al. DNA targeting specificity of RNA-guided Cas9 nucleases. Nat. Biotechnol. 2013, 31, 827-832. [CrossRef] [PubMed]

3. Bortesi, L.; Fischer, R. The CRISPR/Cas9 system for plant genome editing and beyond. Biotechnol. Adv. 2015, 33, 41-52. [CrossRef] [PubMed] 
4. Grobman, A.; Bonavia, D. Origin, Domestication, and Evolution of Maize; Cambridge University Press (CUP): Cambridge, UK, 2013; pp. 329-486.

5. Li, H.; Wang, M.; Li, W.; He, L.; Zhou, Y.; Zhu, J.; Che, R.; Warburton, M.L.; Yang, X.; Yan, J. Genetic variants and underlying mechanisms influencing variance heterogeneity in maize. Plant J. 2020, 103, 1089-1102. [CrossRef] [PubMed]

6. Barrangou, R.; Doudna, J. Applications of CRISPR technologies in research and beyond. Nat. Biotechnol. 2016, 34, 933-941. [CrossRef]

7. Xie, S.; Shen, B.; Zhang, C.; Huang, X.; Zhang, Y. sgRNAcas9: A software package for designing CRISPR sgRNA and evaluating potential off-target cleavage sites. PLOS ONE 2014, 9, e100448. [CrossRef]

8. Metje-Sprink, J.; Menz, J.; Modrzejewski, D.; Sprink, T. DNA-free genome editing: Past, present and future. Front. Plant Sci. 2019, 9. [CrossRef]

9. Liu, Q.; Yuan, Y.; Zhu, F.; Hong, Y.; Ge, R. Efficient genome editing using CRISPR/Cas9 ribonucleoprotein approach in cultured Medaka fish cells. Biol. Open 2018, 7, bio035170. [CrossRef]

10. Kanchiswamy, C.N. DNA-free genome editing methods for targeted crop improvement. Plant Cell Rep. 2016, 35, 1469-1474. [CrossRef]

11. Agarwal, A.; Yadava, P.; Kumar, K.; Singh, I.; Kaul, T.; Pattanayak, A.; Agrawal, P.K. Insights into maize genome editing via CRISPR/Cas9. Physiol. Mol. Biol. Plants 2018, 24, 175-183. [CrossRef]

12. Woo, J.W.; Kim, J.; Kwon, S.I.; Corvalan, C.; Cho, S.W.; Kim, H.; Kim, S.-G.; Kim, S.T.; Choe, S.; Kim, J.-S. DNA-free genome editing in plants with preassembled CRISPR-Cas9 ribonucleoproteins. Nat. Biotechnol. 2015, 33, 1162-1164. [CrossRef] [PubMed]

13. Malnoy, M.; Viola, R.; Jung, M.-H.; Koo, O.-J.; Kim, S.; Kim, J.-S.; Velasco, R.; Kanchiswamy, C.N. DNA-free genetically edited grapevine and apple protoplast using CRISPR/Cas9 Ribonucleoproteins. Front. Plant Sci. 2016, 7. [CrossRef] [PubMed]

14. Subburaj, S.; Chung, S.J.; Lee, C.; Ryu, S.-M.; Kim, D.H.; Kim, J.-S.; Bae, S.; Lee, G. Site-directed mutagenesis in Petunia $\times$ hybrida protoplast system using direct delivery of purified recombinant Cas9 ribonucleoproteins. Plant Cell Rep. 2016, 35, 1535-1544. [CrossRef] [PubMed]

15. Andersson, M.; Turesson, H.; Olsson, N.; Fält, A.-S.; Ohlsson, P.; González, M.N.; Samuelsson, M.; Hofvander, P.; Olsson, P. Genome editing in potato via CRISPR-Cas9 ribonucleoprotein delivery. Physiol. Plant. 2018, 164, 378-384. [CrossRef]

16. Svitashev, S.; Schwartz, C.; Lenderts, B.; Young, J.K.; Cigan, A.M. Genome editing in maize directed by CRISPR-Cas9 ribonucleoprotein complexes. Nat. Commun. 2016, 7, 13274. [CrossRef]

17. Liang, Z.; Zong, Y.; Gao, C. An efficient targeted mutagenesis system using CRISPR/Cas in monocotyledons. Curr. Protoc. Plant Biol. 2016, 1, 329-344. [CrossRef]

18. Char, S.N.; Neelakandan, A.; Nahampun, H.; Frame, B.; Main, M.; Spalding, M.H.; Becraft, P.W.; Meyers, B.C.; Walbot, V.; Wang, K.; et al. An agrobacterium-delivered CRISPR/Cas9 system for high-frequency targeted mutagenesis in maize. Plant Biotechnol. J. 2016, 15, 257-268. [CrossRef]

19. Feng, C.; Su, H.; Bai, H.; Wang, R.; Liu, Y.; Guo, X.; Liu, C.; Zhang, J.; Yuan, J.; Birchler, J.A.; et al. High-efficiency genome editing using a dmc1 promoter-controlled CRISPR/Cas9 system in maize. Plant Biotechnol. J. 2018, 16, 1848-1857. [CrossRef]

20. Dong, L.; Qi, X.; Zhu, J.; Liu, C.; Zhang, X.; Cheng, B.; Mao, L.; Xie, C. Supersweet and waxy: Meeting the diverse demands for specialty maize by genome editing. Plant Biotechnol. J. 2019, 17, 1853-1855. [CrossRef]

21. Sheen, J. Molecular mechanisms underlying the differential expression of maize pyruvate, orthophosphate dikinase genes. Plant Cell 1991, 3, 225-245.

22. Sanger, F.; Nicklen, S.; Coulson, A.R. DNA sequencing with chain-terminating inhibitors. Proc. Natl. Acad. Sci. USA 1977, 74, 5463-5467. [CrossRef] [PubMed]

23. Hsiau, T.; Conant, D.; Rossi, N.; Maures, T.; Waite, K.; Yang, J.; Joshi, S.; Kelso, R.; Holden, K.; Enzmann, B.L.; et al. Inference of crispr edits from sanger trace data. bioRxiv 2019, 251082. [CrossRef]

24. Svitashev, S.; Young, J.K.; Schwartz, C.; Gao, H.; Falco, S.C.; Cigan, A.M. Targeted mutagenesis, precise gene editing, and site-specific gene insertion in maize using Cas9 and guide RNA. Plant Physiol. 2015, 169, 931-945. [CrossRef] [PubMed]

25. Lin, C.-S.; Hsu, C.; Yang, L.; Lee, L.; Fu, J.; Cheng, Q.; Wu, F.; Hsiao, H.C.-W.; Zhang, Y.; Zhang, R.; et al. Application of protoplast technology to CRISPR/Cas9 mutagenesis: From single-cell mutation detection to mutant plant regeneration. Plant Biotechnol. J. 2018, 16, 1295-1310. [CrossRef] [PubMed] 
26. Bortesi, L.; Zhu, C.; Zischewski, J.; Perez, L.; Bassié, L.; Nadi, R.; Forni, G.; Lade, S.B.; Soto, E.; Jin, X.; et al. Patterns of CRISPR/Cas9 activity in plants, animals and microbes. Plant Biotechnol. J. 2016, 14, 2203-2216. [CrossRef]

27. Kim, S.; Kim, D.; Cho, S.W.; Kim, J.; Kim, J.; Kim, J.-S. Highly efficient RNA-guided genome editing in human cells via delivery of purified Cas9 ribonucleoproteins. Genome Res. 2014, 24, 1012-1019. [CrossRef]

28. Braatz, J.; Harloff, H.-J.; Mascher, M.; Stein, N.; Himmelbach, A.; Harloff, H.-J. CRISPR-Cas9 targeted mutagenesis leads to simultaneous modification of different homoeologous gene copies in polyploid oilseed rape (Brassica napus). Plant Physiol. 2017, 174, 935-942. [CrossRef]

29. Sandhya, D.; Jogam, P.; Allini, V.R.; Abbagani, S.; Alok, A. The present and potential future methods for delivering CRISPR/Cas9 components in plants. J. Genet. Eng. Biotechnol. 2020, 18, 1-11. [CrossRef]

30. Wada, N.; Ueta, R.; Osakabe, Y.; Osakabe, K. Precision genome editing in plants: State-of-the-art in CRISPR/Cas9-based genome engineering. BMC Plant Biol. 2020, 20, 1-12. [CrossRef]

31. Liang, Z.; Chen, K.; Li, T.; Zhang, Y.; Wang, Y.; Zhao, Q.; Liu, J.; Zhang, H.; Liu, C.; Ran, Y.; et al. Efficient DNA-free genome editing of bread wheat using CRISPR/Cas9 ribonucleoprotein complexes. Nat. Commun. 2017, 8, 14261. [CrossRef]

32. Murovec, J.; Guček, K.; Bohanec, B.; Avbelj, M.; Jerala, R. DNA-free genome editing of brassica oleracea and B. rapa protoplasts using CRISPR-Cas9 Ribonucleoprotein complexes. Front. Plant Sci. 2018, 9. [CrossRef] [PubMed]

33. Toda, E.; Koiso, N.; Takebayashi, A.; Ichikawa, M.; Kiba, T.; Osakabe, K.; Osakabe, Y.; Sakakibara, H.; Kato, N.; Okamoto, T. An efficient DNA- and selectable-marker-free genome-editing system using zygotes in rice. Nat. Plants 2019, 5, 363. [CrossRef] [PubMed]

34. Liang, Z.; Zhang, K.; Chen, K.; Gao, C. Targeted Mutagenesis in Zea mays Using TALENs and the CRISPR/Cas System. J. Genet. Genomics 2014, 41, 63-68. [CrossRef]

35. Xing, H.; Dong, L.; Wang, Z.; Zhang, H.; Han, C.; Liu, B.; Wang, X.; Chen, Q. A CRISPR/Cas9 toolkit for multiplex genome editing in plants. BMC Plant Biol. 2014, 14, 327. [CrossRef]

36. Qi, W.; Zhu, T.; Tian, Z.; Li, C.; Zhang, W.; Song, R. High-efficiency CRISPR/Cas9 multiplex gene editing using the glycine tRNA-processing system-based strategy in maize. BMC Biotechnol. 2016, 16, 58. [CrossRef]

37. Zhu, J.; Song, N.; Sun, S.; Yang, W.; Zhao, H.; Song, W.; Lai, J. Efficiency and inheritance of targeted mutagenesis in maize using CRISPR-Cas9. J. Genet. Genomics 2016, 43, 25-36. [CrossRef] [PubMed]

38. Shi, J.; Gao, H.; Wang, H.; Lafitte, H.R.; Archibald, R.L.; Yang, M.; Hakimi, S.M.; Mo, H.; Habben, J.E. ARGOS8 variants generated by CRISPR-Cas9 improve maize grain yield under field drought stress conditions. Plant Biotechnol. J. 2017, 15, 207-216. [CrossRef] [PubMed]

39. Chen, R.; Xu, Q.; Liu, Y.; Zhang, J.; Ren, D.; Wang, G.; Liu, Y. Generation of transgene-free maize male sterile lines using the CRISPR/Cas9 system. Front. Plant Sci. 2018, 9. [CrossRef] [PubMed]

40. Lee, K.; Zhang, Y.; Kleinstiver, B.P.; Guo, J.A.; Aryee, J.; Miller, J.; Malzahn, A.; Zarecor, S.; Lawrence-Dill, C.J.; Joung, J.L.; et al. Activities and specificities of CRISPR/Cas9 and Cas12a nucleases for targeted mutagenesis in maize. Plant Biotechnol. J. 2019, 17, 362-372. [CrossRef]

41. Kelliher, T.; Starr, D.; Su, X.; Tang, G.; Chen, Z.; Carter, J.; Wittich, P.E.; Dong, S.; Green, J.; Burch, E. One-step genome editing of elite crop germplasm during haploid induction. Nat. Biotechnol. 2019, 37, 287-292. [CrossRef]

42. Doll, N.M.; Gilles, L.M.; Gérentes, M.F.; Richard, C.; Just, J.; Fierlej, Y.; Borrelli, V.G.M.; Gendrot, G.; Ingram, C.G.; Rogowsky, P.M. Single and multiple gene knockouts by CRISPR-Cas9 in maize. Plant Cell Rep. 2019, 38, 487-501. [CrossRef] [PubMed]

43. Wu, Q.; Xu, F.; Liu, L.; Char, S.N.; Ding, Y.; Je, B.I.; Schmelz, E.; Yang, B.; Jackson, D. The maize heterotrimeric $\mathrm{G}$ protein $\beta$ subunit controls shoot meristem development and immune responses. Proc. Natl. Acad. Sci. USA 2019, 117, 1799-1805. [CrossRef] [PubMed]

44. Liu, H.; Jian, L.; Xu, J.; Zhang, Q.; Zhang, M.; Jin, M.; Peng, Y.; Yan, J.; Han, B.; Liu, J.; et al. High-throughput CRISPR/Cas9 mutagenesis streamlines trait gene identification in maize. Plant Cell 2020, 32, 1397-1413. [CrossRef] [PubMed]

45. Gao, H.; Gadlage, M.J.; Lafitte, H.R.; Lenderts, B.; Yang, M.; Schroder, M.; Farrell, J.; Snopek, K.; Peterson, D.; Feigenbutz, L.; et al. Superior field performance of waxy corn engineered using CRISPR-Cas9. Nat. Biotechnol. 2020, 38, 579-581. [CrossRef] 
46. Gao, H.; Mutti, J.; Young, J.K.; Yang, M.; Schroder, M.; Lenderts, B.; Wang, L.; Peterson, D.; Clair, G.S.; Jones, S.; et al. Complex trait loci in maize enabled by CRISPR-Cas9 mediated gene insertion. Front. Plant Sci. 2020, 11. [CrossRef]

47. Barone, P.; Wu, E.; Lenderts, B.; Anand, A.; Gordon-Kamm, W.; Svitashev, S.; Kumar, S. Efficient gene targeting in maize using inducible CRISPR-Cas9 and marker-free donor template. Mol. Plant 2020, 13. [CrossRef]

48. Zhang, J.; Zhang, X.; Chen, R.; Yang, L.; Fan, K.; Liu, Y.; Wang, G.; Ren, Z.; Liu, Y. Generation of transgene-free Semidwarf maize plants by gene editing of gibberellin-oxidase20-3 using CRISPR/Cas9. Front. Plant Sci. 2020, 11. [CrossRef]

49. Park, J.; Choe, S. DNA-free genome editing with preassembled CRISPR/Cas9 ribonucleoproteins in plants. Transgenic Res. 2019, 28, 61-64. [CrossRef]

50. Vu, G.T.H.; Cao, X.H.; Fauser, F.; Reiss, B.; Puchta, H.; Schubert, I. Endogenous sequence patterns predispose the repair modes of CRISPR/Cas9-induced DNA double-stranded breaks in Arabidopsis thaliana. Plant J. 2017, 92, 57-67. [CrossRef]

51. Agapito-Tenfen, S.Z.; Okoli, A.S.; Bernstein, M.J.; Wikmark, O.-G.; Myhr, A.I. Revisiting risk governance of GM plants: The need to consider new and emerging gene-editing techniques. Front. Plant Sci. $2018,9$. [CrossRef]

(C) 2020 by the authors. Licensee MDPI, Basel, Switzerland. This article is an open access article distributed under the terms and conditions of the Creative Commons Attribution (CC BY) license (http://creativecommons.org/licenses/by/4.0/). 